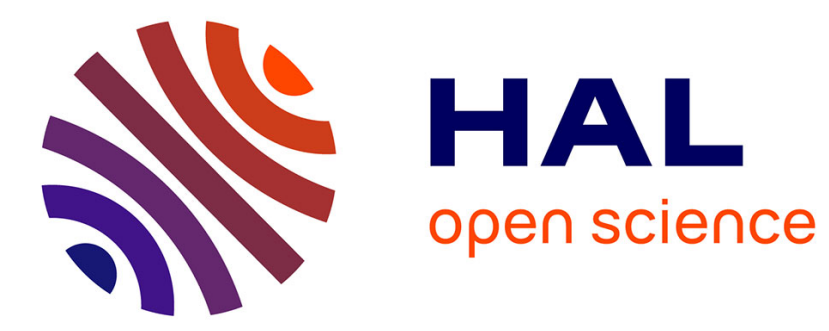

\title{
Engineering the interfacial adhesion in basalt/epoxy composites by plasma polymerization
}

M.C. C Seghini, F. Touchard, F. Sarasini, V. Cech, L. Chocinski-Arnault, D. Mellier, J. Tirillò, M.P. P Bracciale, M. Zvonek

\section{- To cite this version:}

M.C. C Seghini, F. Touchard, F. Sarasini, V. Cech, L. Chocinski-Arnault, et al.. Engineering the interfacial adhesion in basalt/epoxy composites by plasma polymerization. Composites Part A: Applied Science and Manufacturing, 2019, 122, pp.67-76. 10.1016/j.compositesa.2019.04.013 . hal-02282563

\section{HAL Id: hal-02282563 https://hal.science/hal-02282563}

Submitted on 16 Nov 2020

HAL is a multi-disciplinary open access archive for the deposit and dissemination of scientific research documents, whether they are published or not. The documents may come from teaching and research institutions in France or abroad, or from public or private research centers.
L'archive ouverte pluridisciplinaire HAL, est destinée au dépôt et à la diffusion de documents scientifiques de niveau recherche, publiés ou non, émanant des établissements d'enseignement et de recherche français ou étrangers, des laboratoires publics ou privés. 


\title{
ENGINEERING THE INTERFACIAL ADHESION IN BASALT/EPOXY COMPOSITES BY PLASMA POLYMERIZATION
}

\author{
M.C. Seghini ${ }^{1}$, F. Touchard ${ }^{2}$, F. Sarasini ${ }^{1}$, V. Cech $^{3}$, L. Chocinski-Arnault ${ }^{2}$, D. Mellier ${ }^{2}$, J. Tirillò $^{1}$, \\ M.P. Bracciale ${ }^{1}$, M. Zvonek ${ }^{3}$ \\ ${ }^{1}$ Department of Chemical Engineering Materials Environment, Sapienza-Università di Roma, Via \\ Eudossiana 18, 00184 Rome, Italy \\ ${ }^{2}$ Institut PPRIME, CNRS-ENSMA, Université de Poitiers, Département Physique et Mécanique des \\ Matériaux, ENSMA, 1, Av. Clément Ader, B.P. 40109, 86961 Futuroscope Cedex, France \\ ${ }^{3}$ Institute of Materials Chemistry, Faculty of Chemistry, Brno University of Technology, Purkynova 118, CZ- \\ 61200 Brno, Czech Republic
}

\begin{abstract}
In an attempt to improve mechanical properties of basalt fibre/epoxy composites, the present work provides a comparison between the effects of a commercial coupling agent, a thermal de-sizing treatment and a plasma polymerization process on the fibre/matrix interfacial strength. The different basalt fibres were characterized in terms of surface morphology, by FE-SEM observations, and chemical composition, performing FT-IR analysis. The interfacial adhesion has been investigated by single fibre fragmentation test (SFFT) on single fibre composite samples. The plasma polymerization process was able to produce a homogeneous tetravinylsilane (pp-TVS) coating on the surface of basalt fibres, which resulted in a significant increase in the adhesion between basalt fibre and epoxy resin. The surface roughness of the untreated and treated basalt fibres has been measured by Atomic Force Microscopy (AFM) and a relationship between the surface roughness and the adhesion quality between the basalt fibres and the epoxy matrix was found. High-resolution microtomography ( $\mu$-CT) has been used to support the analysis of the damage modes during fragmentation tests.
\end{abstract}

Keywords: Basalt fibres; Fibre/matrix bond; Interface/interphase; CT analysis; Plasma-Enhanced Chemical Vapor Deposition 


\section{Introduction}

The interest in basalt fibre reinforced composites cannot be any longer confined to the academic environment, as confirmed by a recent market report [1] according to which the global basalt fibre market is estimated to grow at a CAGR (Compound Annual Growth Rate) of around 14.2\% over the next decade to reach approximately $\$ 392.5$ million by 2025 . Basalt fibre is now well established as a competitor to the more widely used glass fibre as a reinforcement for polymer matrices [2][3]. Basalt fibres (BFs) feature a natural origin that, if combined with mechanical properties at least comparable with those of traditional E-glass fibres, may at the same time overcome the environmental issues and the typical limitations of vegetal natural fibres, such as flax, hemp, jute, sisal and so forth. Unfortunately, the mechanical performance of a fibrous composite is not only dictated by the properties of the single constituents (fibres and matrix), but also by fibre/matrix adhesion [4]. The fiber/matrix interfacial domain is a decisive constituent of fibre reinforced composites and, depending on the characteristics of such domain, composite with a brittle or a damage tolerant behaviour may be designed. Thus, several requirements in terms of strength and toughness, which may seem to oppose to each other, have to be fulfilled. As the fibre/matrix adhesion is a well-known key factor of composite performance, its engineering design has attracted the interest from both academia and industry [5]-[7]. A great deal of research has been carried out into the interface between glass fibres and a broad range of polymer matrix materials, but comparatively less attention has been devoted to the basalt fibres due to their quite recent introduction in the composite market, if compared to glass fibres. In addition, much of the sizing used on basalt fibres is inherited from glass fibre technology, thus being not necessarily designed for basalt fibres [8]. All commercially available glass and basalt fibres are surface treated and/or coated during their manufacturing steps with a sizing mainly deposited by a wet chemical process. It has been reported that the resulting coating is not of a consistent thickness and uniformity [9], the molecules of silane coupling agents are prone to selfcondense, forming siloxane oligomers rather than a complete bonding with the fibre surface [10] and, most notably, only a limited fraction (in the range 10-20\%) of the total sizing is bonded to the fibre surface [11]. When dealing with enhancements of interfacial adhesion, several strategies have been proposed over the years for basalt fibres, including: (i) incorporation of nanofillers into sizing formulations [12][13], (ii) bulk modification of the matrices by using coupling agents [14][15] or by nanofillers dispersion [16]. Another way to improve the performance of composites via interface engineering is represented by the plasma-chemical process, which is considered as one of the most effective methods to optimize both strength and toughness if materials for coating and process parameters are carefully selected [17][18]. Unlike plasma treatment, which is used to increase the surface roughness and introduce functional groups into the surface layer of fibres with limited 
increase in interfacial shear strength [19], the plasma polymerization process is able to produce homogeneous and pinhole free films on the fibres in a clean environment without use of solvents and at low temperature, thus minimizing the risks of mechanical properties degradation of the substrate. This process proved to be successful for glass fibres [20]-[23] but no study, to the best of authors' knowledge, is available on basalt fibres. In this work the surface, morphological and mechanical properties of plasma-polymerized basalt fibres with a tetravinylsilane film have been investigated. Plasma-polymerized organosilicones represent a class of versatile materials with a sound scientific background and their use as a tailored interlayer to improve interfacial adhesion of surface modified basalt fibres in epoxy-based composites is proposed in this experimental work. Comparisons with commercially sized basalt fibres and basalt fibres after sizing removal were made. The adhesion to epoxy matrix was studied by single fibre fragmentation tests (SFFT) coupled with a micro-CT analysis.

\section{Experimental}

\subsection{Materials}

This experimental work has been focused on the improvement of adhesion properties of basalt fibres (BFs) with epoxy matrix. The Epoxy Prime 27 infusion resin and the PRIME 20 slow hardener, both delivered by GURIT, have been selected. The curing process has been carried out with a mixing ratio of 100:28 by weight. A post-curing procedure of $7 \mathrm{~h}$ at $90^{\circ} \mathrm{C}$ has been performed to obtain a fully cross-linked epoxy. A commercial grade of basalt fibre has been used in this work. In particular, a continuous roving of basalt fibres, supplied by Kamenny Vek, with a linear density of 1200 tex has been selected. Basalt fibres were characterized by a nominal diameter of $13 \mu \mathrm{m}$ and the presence of a commercial sizing agent compatible with epoxy resin.

\subsection{Surface Treatments}

\subsubsection{Thermal treatment}

In order to remove the commercial sizing from the basalt surface, fibre bundles were heat treated asreceived in a tube furnace (Lenton Thermal Designs Ltd) at a temperature of $400^{\circ} \mathrm{C}$ in air for $1 \mathrm{~h}$ and then removed from the furnace and allowed to cool in room temperature air [15].

\subsubsection{PECVD process}

After the thermal treatment, a thin polymer film has been deposited on the unsized basalt fibres by Plasma-Enhanced Chemical Vapor Deposition (PECVD) process. Plasma deposition has been carried out in a reactor consisting of a glass tube $100 \mathrm{~cm}$ long and with an inner diameter of $40 \mathrm{~mm}$. The 
plasma system was first evacuated to a basic pressure of about $10^{-4} \mathrm{~Pa}$. Argon gas (99.999\%) was used to clean the plasma reactor and vacuum chamber. The polymer deposition treatment has been divided in two steps: a first non-polymerising gas plasma step, a pre-treatment with oxygen plasma $(5.8 \mathrm{~Pa}, 100 \mathrm{~W})$ for $30 \mathrm{~min}$ to remove contaminants, activate the fibre surface and improve film adhesion, and a second step of polymerising gas plasma, in which tetravinylsilane monomer $\operatorname{Si}(-$ $\left.\mathrm{CH}=\mathrm{CH}_{2}\right)_{4}$ (purity 97\%, Sigma Aldrich) was fragmented and ionized in plasma producing excited species, free radicals and ions which were recombined forming a thin plasma polymer film onto the fibre surface. Tetravinylsilane plasma (3.8 Pa, $10 \mathrm{~W})$ was employed for $15 \mathrm{~min}$.

\subsection{Morphological and chemical characterization}

A morphological investigation of the surface of the untreated, thermally treated and plasma treated basalt fibres has been carried out using a field-emission gun scanning electron microscope (FE-SEM) Zeiss Auriga and a Philips XL40. After single fibre fragmentation tests, the morphology of the single fibre composite fracture surfaces has been investigated. All specimens were sputter coated with chromium prior to each FE-SEM observation to improve image quality. The roughness of the untreated and treated basalt fibres has been measured using a Bruker Dimension Icon AFM, equipped with Nanoscope V controller. A Bruker Tapping Probe cantilever (Sb doped n Si) characterized by an elastic constant of $40 \mathrm{~N} / \mathrm{m}$ and nominal resonance frequency of $300 \mathrm{kHz}$ has been used. Topographic imaging has been acquired in tapping mode on a scan area of $(3 \times 3) \mu \mathrm{m}^{2}$ and using a scan rate between 0.3 and $0.5 \mathrm{~Hz}$. A minimum of three different areas were scanned for each sample and then results averaged. All measurements have been performed in an insulating chamber to avoid acoustic excitation. The roughness of each fibre surface has been measured using root mean square (RMS) roughness after removing the fibre curvature by polynomial fitting. AFM data have been processed using Gwyddion software. The chemical composition of the as-received, thermally treated and plasma treated basalt fibres has been studied by Fourier-transform infrared (FTIR) analysis. Infrared measurements were carried out with a Bruker Vertex 70 spectrometer (Bruker Optik GmbH) equipped with a single reflection Diamond ATR cell. Spectra were recorded with a $3 \mathrm{~cm}^{-1}$ spectral resolution in the mid infrared range $\left(400-4000 \mathrm{~cm}^{-1}\right)$ using 512 scans.

\subsection{Tensile testing}

A mechanical characterization has been performed on the untreated (as received), thermally treated and plasma treated basalt fibres. Tensile properties have been determined by single fibre tensile tests in accordance with ASTM C-1557. Tensile tests were carried out at room temperature using a Zwick/Roell Z010 machine equipped with a $100 \mathrm{~N}$ load cell. Each test has been performed in 
displacement control at a cross-head speed of $2 \mathrm{~mm} / \mathrm{min}$. Individual basalt fibres were carefully separated by hand from the different fibre bundles and glued onto a card tab with a central window cut out to match the gauge length of 20,30 and $40 \mathrm{~mm}$. At least 30 fibres were tested for each type of basalt fibre. Before testing, all fibres were conditioned at $45{ }^{\circ} \mathrm{C}$ for $24 \mathrm{~h}$. Fibre diameter was evaluated through an optical microscope Nikon Eclipse 150L equipped with the image analysis software Lucia Measurement. Because of the small dimension of fibres, the use of standard extensometers has not been possible. The actual specimen elongation in the gauge length was determined by subtracting the displacement associated with the system compliance from the total cross-head displacement. The system compliance was measured according to ASTM C1557 by obtaining the force versus displacement behaviour of the fibres at three gauge lengths, namely 20 $\mathrm{mm}, 30 \mathrm{~mm}$ and $40 \mathrm{~mm}$. For each gauge length a minimum of 30 fibres were tested.

\subsection{Single fibre fragmentation tests}

The single fibre fragmentation test has been used in a previous experimental work to assess the interfacial properties of flax yarns with epoxy matrix [24]. A metallic mould has been used for the manufacture of composite specimens reinforced with a single basalt fibre aligned along the load direction. A single basalt fibre was carefully extracted from basalt rovings and positioned in the mould for composite manufacture. Before casting, basalt fibres were conditioned at $45^{\circ} \mathrm{C}$ for $24 \mathrm{~h}$. A dog bone specimen, characterised by a reduced gage section with a length of $15 \mathrm{~mm}$, a thickness of $2 \mathrm{~mm}$ and a width of $3 \mathrm{~mm}$, has been produced. The fragmentation testing was performed with an Instron E1000 ElectroPuls test machine with a load cell of $2 \mathrm{kN}$, using a crosshead speed of $0.005 \mathrm{~mm} / \mathrm{min}$. The loading phase was stopped if the specimen failed, or when the fragmentation saturation level was achieved. This last case was defined when no new fibre breaks appeared during a subsequent strain increase by $0.5 \%$. After each fragmentation test, all the fragment lengths were determined by using a ZEISS Axio Imager optical microscope. To study in a proper manner the interfacial debonding phenomena between the basalt fibre and the epoxy resin, a birefringence analysis has been performed for the untreated basalt fibre/epoxy, the thermally treated basalt fibre/epoxy and the tetravinylsilane plasma treated basalt fibre/epoxy systems. During optical microscopy observation, the fragmented single fibre composite samples were placed into a circular polariscope in order to observe the stress state near the fibre breaks and the interface between the single basalt fibre and the matrix.

\subsection{Micro-CT apparatus}

Image acquisition has been performed using an UltraTom CT scanner manufactured by RX Solutions (France). The system consists in a Hamamatsu open type microfocus X-ray tube operating at 20-100 
$\mathrm{kV} /$ 0-200 $\mu \mathrm{A}$, within a maximum power of $20 \mathrm{~W}$ (Configuration with a Lanthanum hexaboride filament). A precision object manipulator with two translations and one rotation facilitates rotating the sample for acquisition of tomographic data, and displacement along the optical axis to adjust the magnification. X-rays generated by the source diverge at an angle providing a cone-beam, thus samples can be imaged at various geometric magnifications by moving the sample close to the source to provide high resolution mode or close to the detector to provide low resolution measurements. The generator and the detector are also mobile to cover a large range of magnifications. A $1.5 \mu \mathrm{m}$ resolution has been used in this work, with an accelerating voltage of $50 \mathrm{kV}$ and a beam current of $157 \mu \mathrm{A}$. This X-ray detector consists in an X-ray CsI scintillator screen which is settled on an amorphous silicon layer.

\section{Results and Discussion}

\subsection{Morphological and Chemical analysis}

Comparing SEM micrographs of the lateral surfaces of the as-received and the heat-treated basalt fibres, Figure $1 \mathrm{a}-\mathrm{b}$, it is possible to confirm the ability of the heat treatment in removing or at least deteriorating the protective sizing layer, exposing the superficial defects, present on the as received fibres. From Fig. 1c it is possible to see that a continuous pp-TVS film has been produced by plasma polymerization process, which is able to spread homogeneously all over the lateral surface of basalt fibre. Some surface irregularities of pp-TVS film randomly dispersed along the fibre surface have been found, Fig. 1c. As reported by Cech et al. [25], the presence of these surface features may be connected with the plasma polymerization mechanism. In particular, it is possible that defects or surface irregularities present on the surface of the thermally treated basalt fibers may operate as nucleation centers of pp-TVS deposits. 

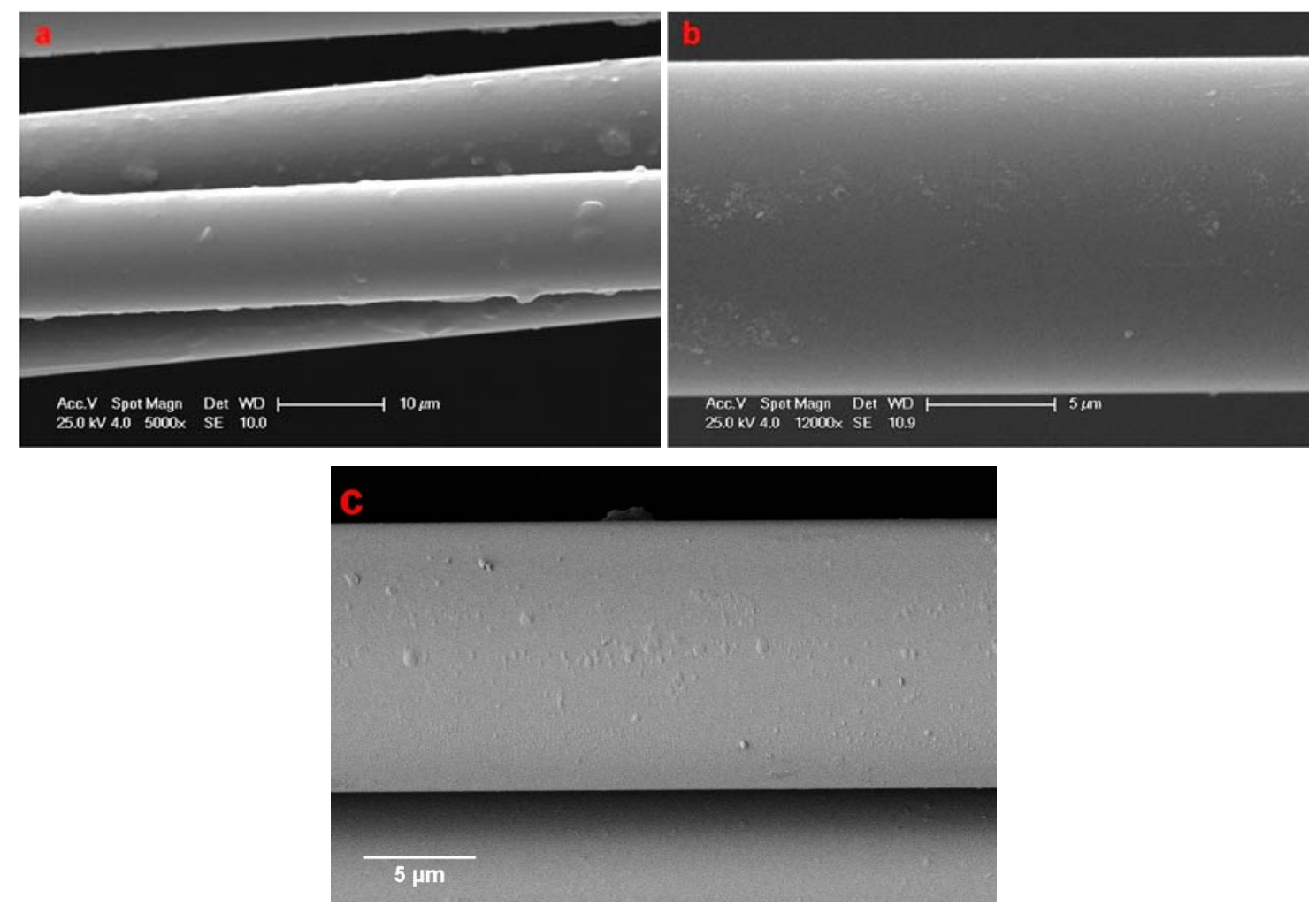

Figure 1 Scanning electron micrographs detailing the lateral surface of untreated (a), thermally treated (b), plasma treated (c) basalt fibres.

The presence of the pp-TVS film has been demonstrated by intentionally producing some scratches on the fibre surface, Figure $2 \mathrm{a}-\mathrm{b}$.
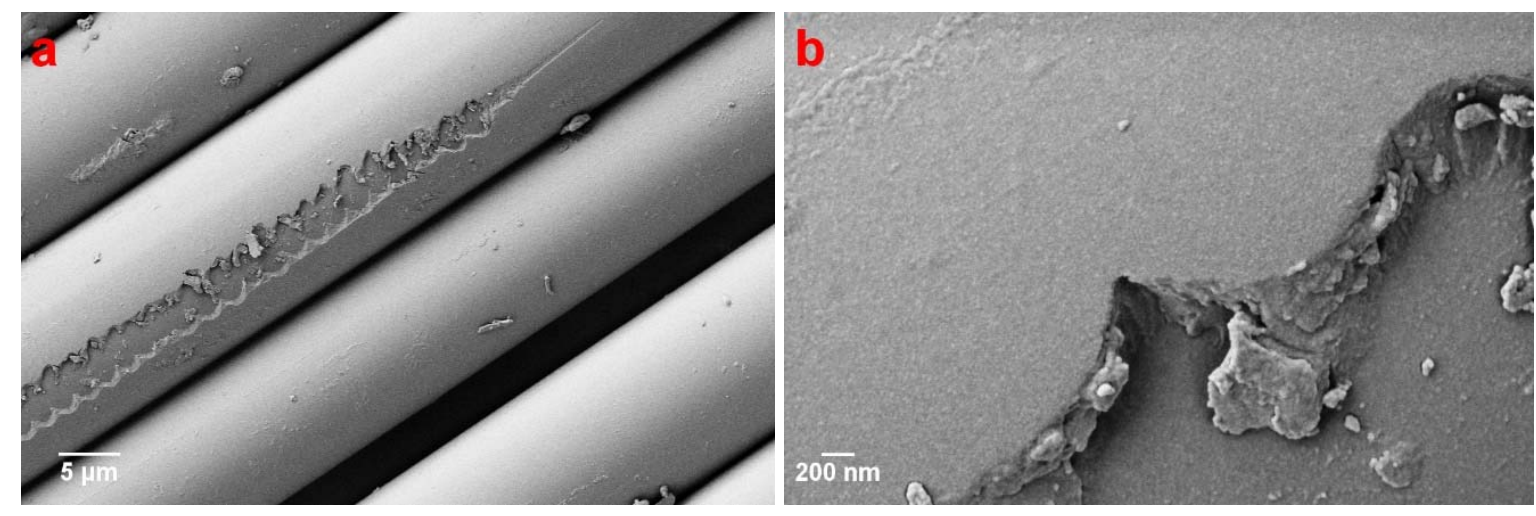

Figure 2 Scanning electron micrographs of plasma polymer coated basalt fibres: (a) micrograph showing several uniformly plasma treated fibres and an intentionally scratched fibre, (b) with a detailed view of the damaged polymer film.

The chemical composition of the treated and untreated basalt fibres was investigated employing the Fourier Transform Infrared Spectroscopy. The FT-IR spectra of as-received, thermally treated and plasma treated basalt fibres are shown in Fig. 3. 


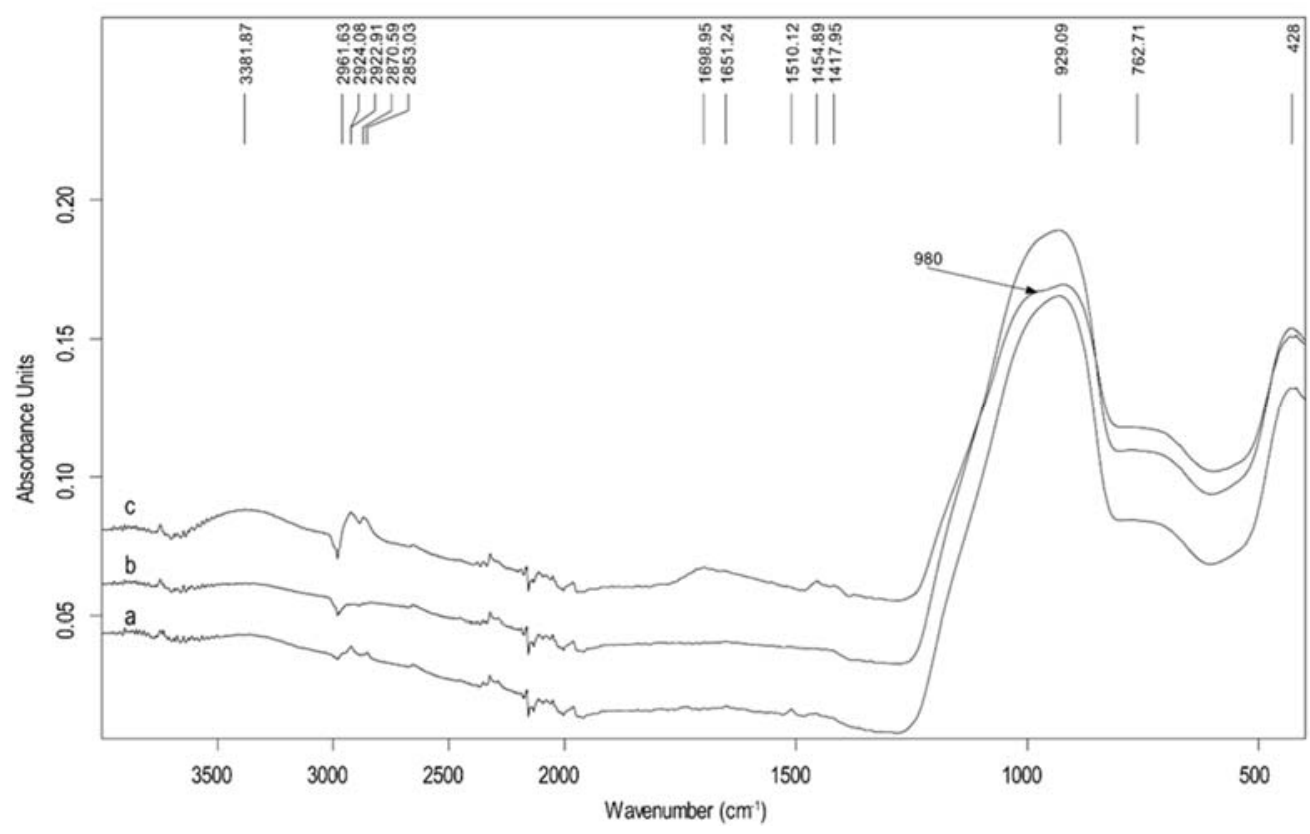

Figure 3 Infrared spectra of untreated (a), thermally treated (b) and plasma treated (c) basalt fibres.

The spectral analysis revealed that in all samples a group of very strong absorption bands is observed in the region of $1270-600 \mathrm{~cm}^{-1}$, due to the stretching vibrations of the $\mathrm{Al} \backslash \mathrm{O} \backslash \mathrm{Si}$ network. In particular, the absorption bands at $929 \mathrm{~cm}^{-1}$ and $763 \mathrm{~cm}^{-1}$ are due to the $\mathrm{Si}-\mathrm{O}$ asymmetric stretching vibrational mode of $\mathrm{SiO}_{4}$ tetrahedra and $\mathrm{Si}-\mathrm{O}$ or $\mathrm{Si}-\mathrm{O}-\mathrm{Al}$ symmetric bending, respectively [26]. Furthermore, the characteristic bands of $\mathrm{O}=\mathrm{C}-\mathrm{NH}$ of imine at $1650 \mathrm{~cm}^{-1}$, the $-\mathrm{NH}$ bending at $1510 \mathrm{~cm}^{-1}$ and small peaks of $-\mathrm{CH}$ at 2852 and $2924 \mathrm{~cm}^{-1}$ were also visible in the as-received sample (Fig. 3a) [27]. The latter should be due to the presence of the sizing in as-received basalt fibre and upon thermal treatment disappeared (Fig. 3b). Typical infrared bands of plasma-polymerized tetravinylsilane (pp-TVS) films deposited on thermally treated basalt fibres can be seen in Fig. 3c. At the wavenumber range 3700$3100 \mathrm{~cm}^{-1}$ a significant band of -OH occurs. Following, wide bands in the range $3100-2750 \mathrm{~cm}^{-1}$ are due to vibrations of $-\mathrm{CH}_{2}$ and $-\mathrm{CH}_{3}$ groups. Significant bands due to $\mathrm{C}=\mathrm{O}$ vibration at $1699 \mathrm{~cm}^{-1}$, $\mathrm{C}=\mathrm{C}$ stretching at $1651 \mathrm{~cm}^{-1},-\mathrm{CH}_{2}$ scissoring at $1455 \mathrm{~cm}^{-1}$ and $=\mathrm{CH}_{2}$ deformation at $1418 \mathrm{~cm}^{-1}$ in vinyl group can be observed. Finally, an increase in the band belonging to Si-O-Si stretching at 980 $\mathrm{cm}^{-1}$ is clearly visible in plasma-coated sample [21][28][29]. Differences in the surface topography of the different basalt fibres have been found. The RMS roughness results from AFM data are reported in Table 1.

Table 1 Average RMS roughness values for the as-received, thermally treated and plasma treated basalt fibres. 


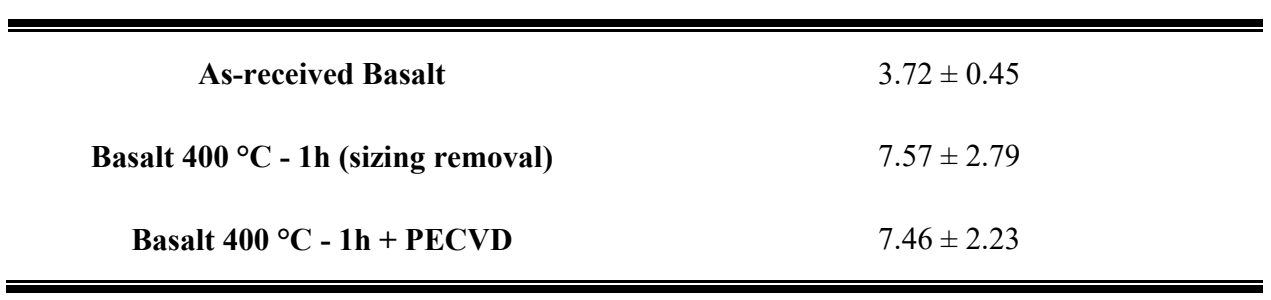

Figure 4 shows the different surface roughness plot for the different basalt fibres. A lower roughness surface has been found locally for the untreated basalt fibres, while an increase in surface roughness has been found for both thermally treated and plasma treated basalt fibres. In the first case, these results indicate that the heat treatment is able to remove, at least partially, the sizing layer present in the commercial fibres, thus exposing surface defects.
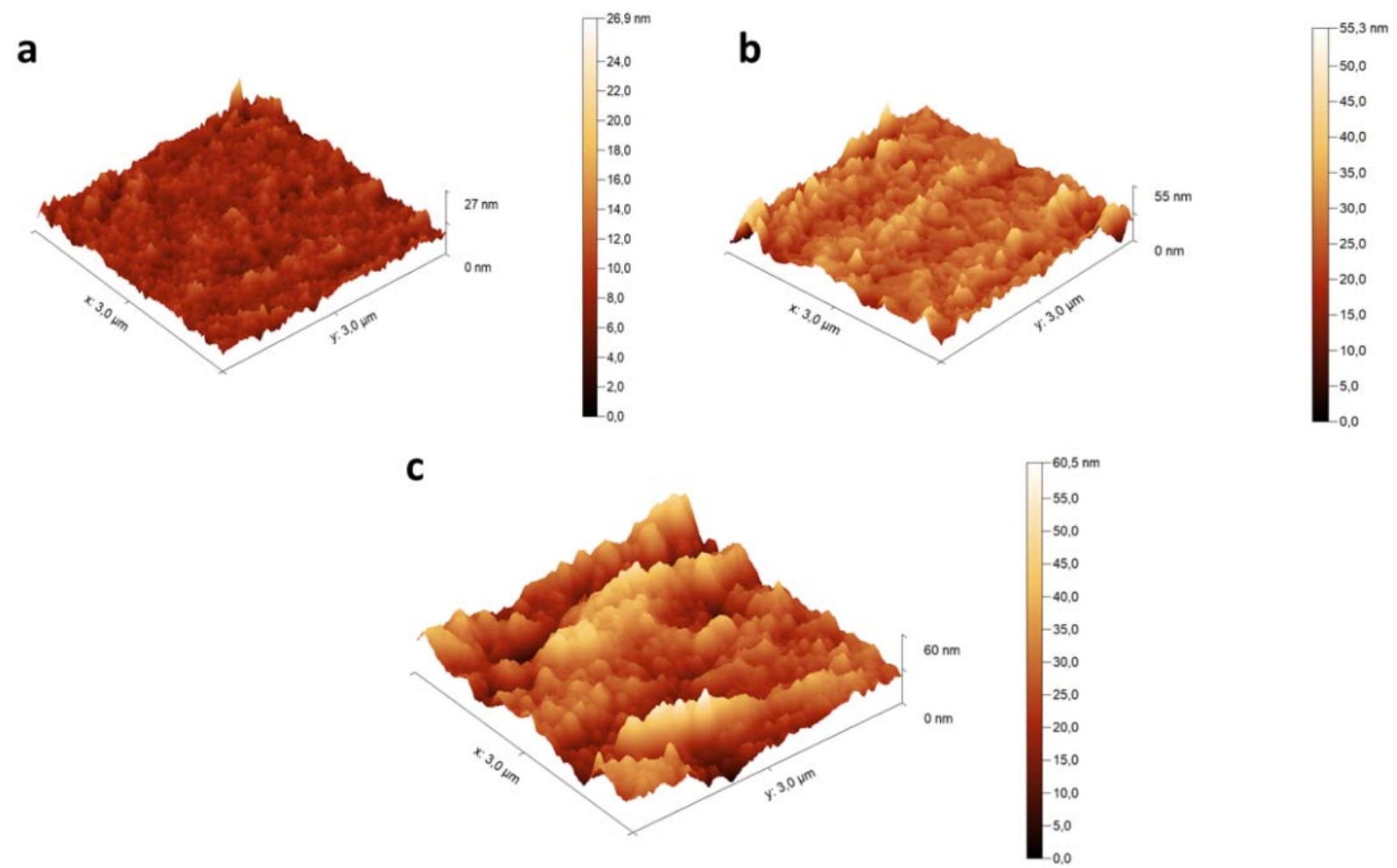

Figure $43 \mathrm{D}$ topography plots of basalt fibres (BFs) : (a) as-received $\mathrm{BFs}$, (b) BFs treated at $400^{\circ} \mathrm{C}$ for $1 \mathrm{~h}$ and (c) $\mathrm{BFs}$ thermally treated at $400^{\circ} \mathrm{C}$ for $1 \mathrm{~h}$ and subsequently treated by PECVD.

After the plasma polymer deposition, the presence of a rougher surface has been highlighted, (Fig. 4c), likely due to the surface irregularities previously described (Fig. 1c).

\subsection{Mechanical characterization}


A comparison between the tensile results found for the commercially sized basalt fibres, the basalt fibres after the thermal sizing removal process and the plasma treated basalt fibres, is presented in Table 2.

Table 2 Summary of tensile properties of untreated and treated basalt fibres.

\begin{tabular}{|c|c|c|c|}
\hline & -Gauge Length $\mathrm{I}_{0}[\mathrm{~mm}]$ & $\overline{\sigma_{\mathrm{f}}[\mathrm{MPa}]}$ & $\overline{\varepsilon_{\mathrm{f}}[\%]}$ \\
\hline \multirow{4}{*}{ As-received Basalt } & 20 & $2515 \pm 277$ & $2.41 \pm 0.32$ \\
\hline & 30 & $2440 \pm 164$ & $2.6 \pm 0.24$ \\
\hline & 40 & $2410 \pm 277$ & $2.5 \pm 0.4$ \\
\hline & 20 & $1197 \pm 311$ & $1.47 \pm 0.43$ \\
\hline \multirow{3}{*}{ Basalt $400{ }^{\circ} \mathrm{C}-1 \mathrm{~h}$} & 30 & $1231 \pm 387$ & $1.42 \pm 0.44$ \\
\hline & 40 & $1113 \pm 296$ & $1.36 \pm 0.34$ \\
\hline & 20 & $2218 \pm 450$ & $2.07 \pm 0.62$ \\
\hline \multirow{2}{*}{$\begin{array}{c}\text { Basalt } 400^{\circ} \mathrm{C}-1 \mathrm{~h}+ \\
\text { PECVD }\end{array}$} & 30 & $1763 \pm 409$ & $1.83 \pm 0.48$ \\
\hline & 40 & $1478 \pm 349$ & $1.81 \pm 0.41$ \\
\hline
\end{tabular}

A first aspect to be highligted is the heating process ability to induce a decrease in the tensile strength of basalt fibres. If the strength values of the untreated and the thermally treated basalt fibres are compared, a significative reduction is found after the treatment at $400^{\circ} \mathrm{C}$ for a duration of $1 \mathrm{~h}$. This result is clearly linked to the protective effect of the sizing agents present on the surface of the commercial basalt fibre. As highlighted by the morphological analysis, Fig. 1b, the heat treatment is able to deteriorate the protective sizing layer of the fibre, producing an exposure of the superficial defects. Zinc et al. [30] have investigated the influence of the sizing layer on the mechanical properties of the fibres because it can fully or partially fill the surface cavities. The exposure to the plasma polymerization process after the heating treatment results in a partial recovery of the tensile properties of fibres. Comparing the results found for the thermally treated and plasma treated basalt fibres, an increase in the tensile strength has been detected after the pp-TVS film deposition. The recovery phenomenon is significant in particular for the basalt fibres tested at a gauge length of $20 \mathrm{~mm}$. Once again, this result may be ascribed to the healing effect of the pp-TVS deposited film on the surface defects of the thermally treated basalt fibres. The experimental results were statistically analysed using a two-parameter Weibull distribution, according to the equation 1 [30]:

$$
\operatorname{Pr}\left(\sigma_{f}\right)=1-\exp \left[-\left(\frac{\sigma_{f}}{\sigma_{0}}\right)^{m}\right]
$$


Where $\operatorname{Pr}\left(\sigma_{\mathrm{f}}\right)$ is the probability of survival of the tensile strength $\sigma_{\mathrm{f}}, \mathrm{m}$ is the Weibull modulus (related to the dispersion of the data) and $\sigma_{0}$ is the characteristic strength. Equation 2 shows the estimator, $\mathrm{P}_{\mathrm{f}}$, used for the probability of failure evaluation:

$$
P_{f}=\frac{i-o .5}{N}
$$

where $N$ is the number of fibres tested and $i$ is the rank of data point for each filament. In table 3 are reported all the Weibull moduli and the characteristic strength values found for the treated and untreated basalt fibres.

Table 3 Weibull distribution parameters for untreated amd treated basalt fibres.

\begin{tabular}{|c|c|c|c|}
\hline & $\begin{array}{c}\text { Gauge Length } I_{0} \\
{[\mathrm{~mm}]}\end{array}$ & Tensile strength $m$ & $\begin{array}{c}\text { Tensile strength } \sigma_{0} \\
{[\mathrm{MPa}]}\end{array}$ \\
\hline \multirow{3}{*}{ As-received Basalt } & 20 & 10.85 & 2634 \\
\hline & 30 & 18.02 & 2513 \\
\hline & 40 & 10.27 & 2530 \\
\hline \multirow{3}{*}{ Basalt $400{ }^{\circ} \mathrm{C}-1 \mathrm{~h}$} & 20 & 4.44 & 1312 \\
\hline & 30 & 3.39 & 1373 \\
\hline & 40 & 4.19 & 1226 \\
\hline \multirow{3}{*}{ Basalt $400^{\circ} \mathrm{C}-1 \mathrm{~h}+$ PECVD } & 20 & 5.78 & 2395 \\
\hline & 30 & 5.32 & 1913 \\
\hline & 40 & 4.84 & 1612 \\
\hline
\end{tabular}

Weibull distribution plots of strength for treated and untreated basalt fibres as a function of gauge length are reported in Figure 5. All the Weibull distribution graphs found for the as-received and for the thermally and plasma treated fibres are characterized by a quasi-linear trend indicating a mechanical behaviour influenced by the presence of a single population of defects. 
a

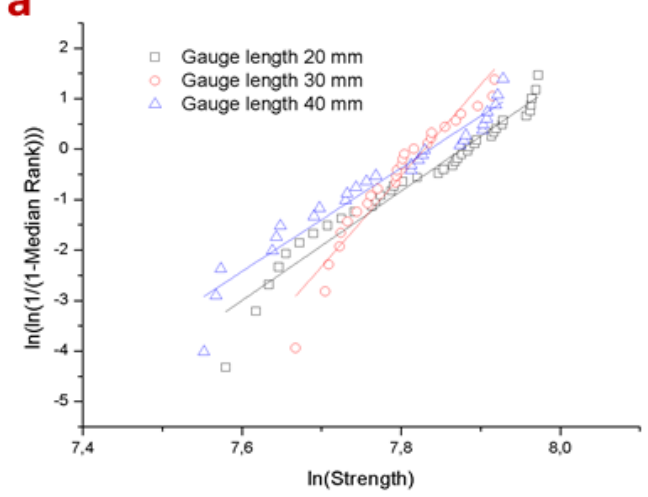

b

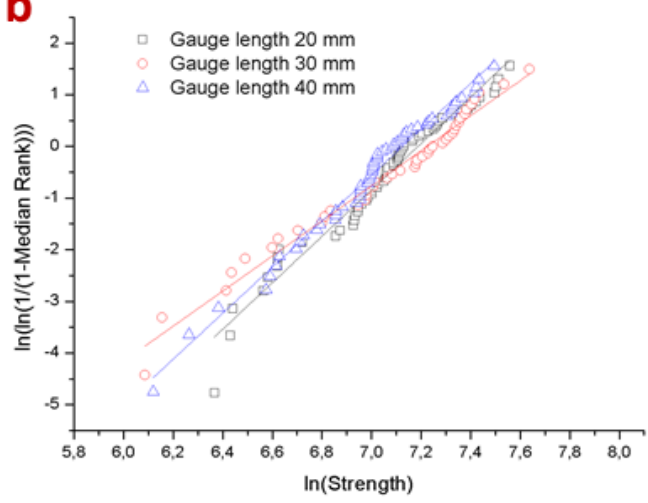

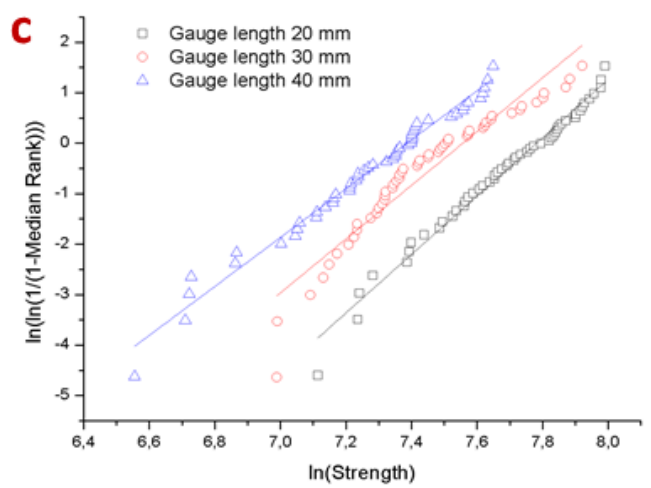

Figure 5 Weibull plots of single fibre strength for the as-received (a), thermally treated (b) and plasma treated basalt fibres (c).

\subsection{Fibre - Matrix adhesion analysis}

The shape of the fibre breaks inside polymer resin is an indicative factor of the adhesion between fibre and matrix. Figure 6 reports the optical micrographs found for the fragmented epoxy samples reinforced with the as-received (Fig. 6a), thermally treated (Fig. 6b) and plasma treated basalt fibres (Fig. 6c).
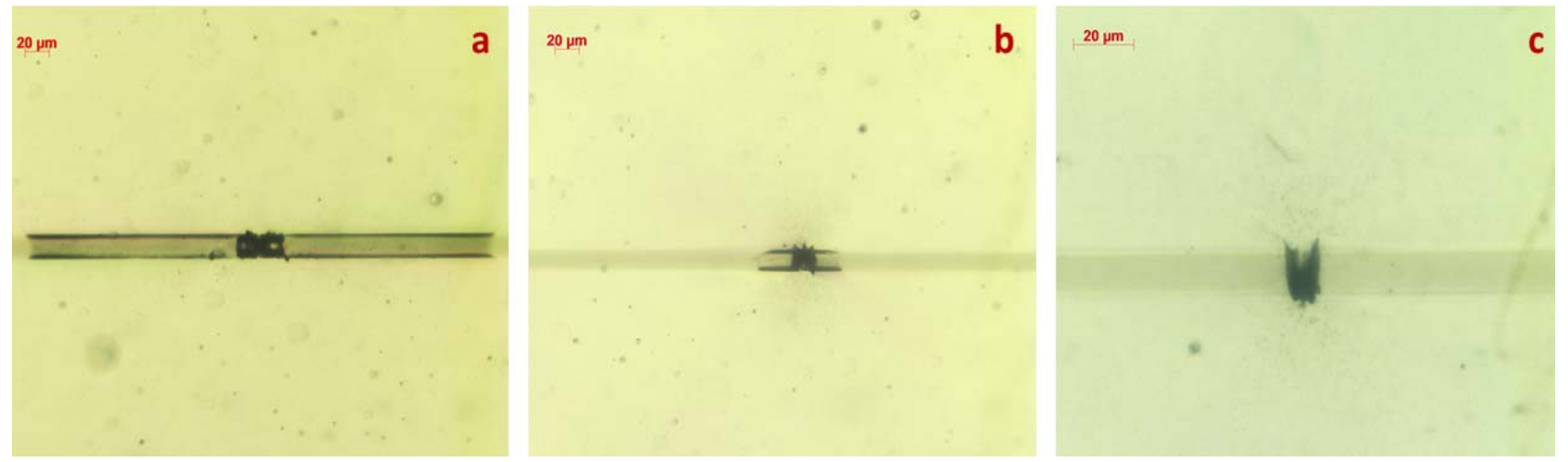

Figure 6 Optical micrographs of the fragmented basalt fibres: (a) as-received, (b) thermally treated and (c) plasma treated basalt fibres. 
The optical micrographs show that, for each sample, a black area corresponding with the fibre break zone has been detected. As reported by Kim et al. [31], when a fibre fails and fractures earlier than the polymer matrix during the fragmentation test, the fibre ends may slip leaving empty space at the point of the fibre break. Micro-CT analysis has been performed on the as received basalt fibre/epoxy and plasma treated basalt fibre/epoxy systems. The results confirmed that the black area found during the optical microscopy investigation corresponds to the empty zone inside the matrix produced during tensile loading, Figure 7.
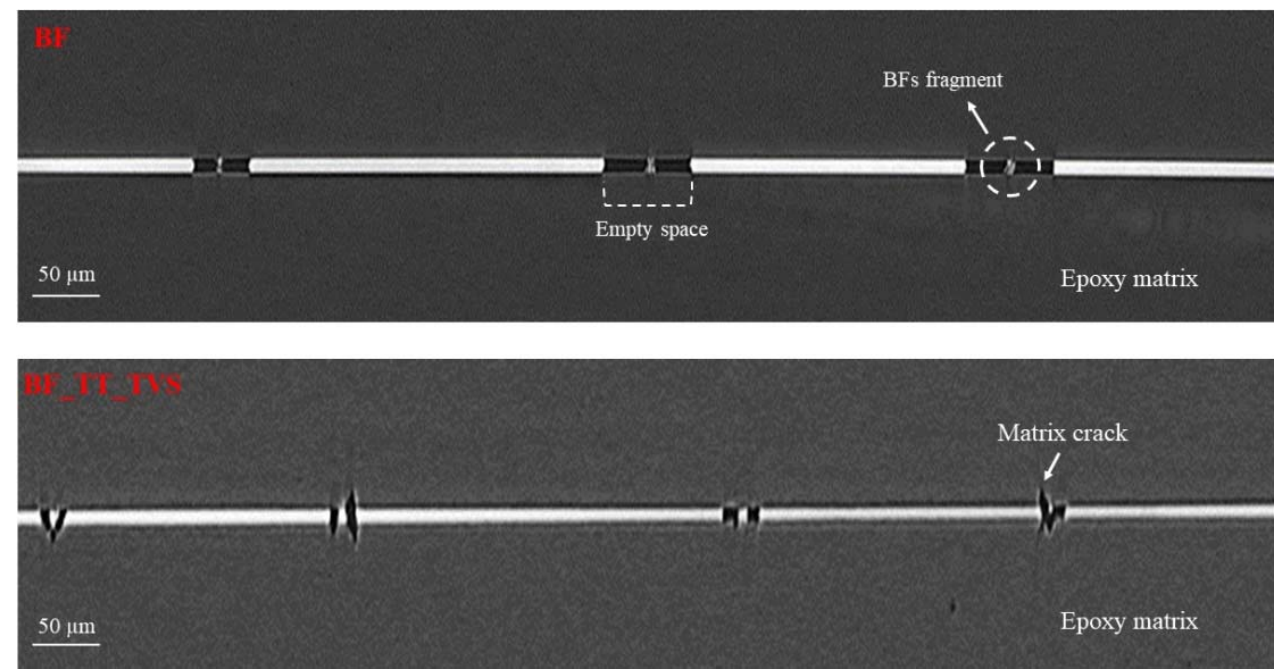

Figure 7 High resolution micro-CT images for as-received basalt fibre/epoxy (BF) and plasma treated basalt fibre/epoxy (BF_TT_TVS) systems.

The microtomography analysis has also shown the presence of fibre fragments inside the empty zones, impossible to be detected by optical microscopy. The untreated basalt fibre/epoxy samples exhibited a shape of breaks characteristic of a weak interface system, characterized by a wide breaking gap. For all the epoxy samples characterized by the presence of the untreated basalt fibres, no breakage extending in the matrix has been observed. On the other hand, both the epoxy samples reinforced with thermally treated and plasma treated basalt fibres were characterized by the presence of a reduced break gap between the fibre ends. As it is possible to see from the micrographs, Fig. 6 b-c, the epoxy matrix cracks forming a characteristic "bat-shape" break zone [32]. This shape is distinctive of a strong interface system. In fact, as reported by Feih et al. [33], in systems characterized by a strong bonding between the fibre and the polymer matrix, a damage of the matrix is introduced in the area around the fibre break producing a narrow breaking area able to propagate towards the matrix. The birefringence method has been used to observe the interfacial debonding phenomena between the different basalt fibres and the epoxy matrix. According to Kim et al. [31], the interfacial 
zone between the fibre and the polymer matrix may be considered as a set of bonding lines. When the single fibre specimen is loaded, some lines near the break zone are disconnected. This specific zone represents the debonding zone between the basalt fibre and the matrix. When the debonding phenomena occur, photoelastic birefringence is formed near the stressed fibre ends. When the single fibre specimen is unloaded, a flat colour zone at the interface between the fibre and the matrix is still visible. Figure 8 a-b and Figure 9 a-b show the birefringence patterns found for the as received basalt fibre/epoxy system and for the single fibre epoxy specimens characterized by the presence of the thermally and plasma treated basalt fibres.
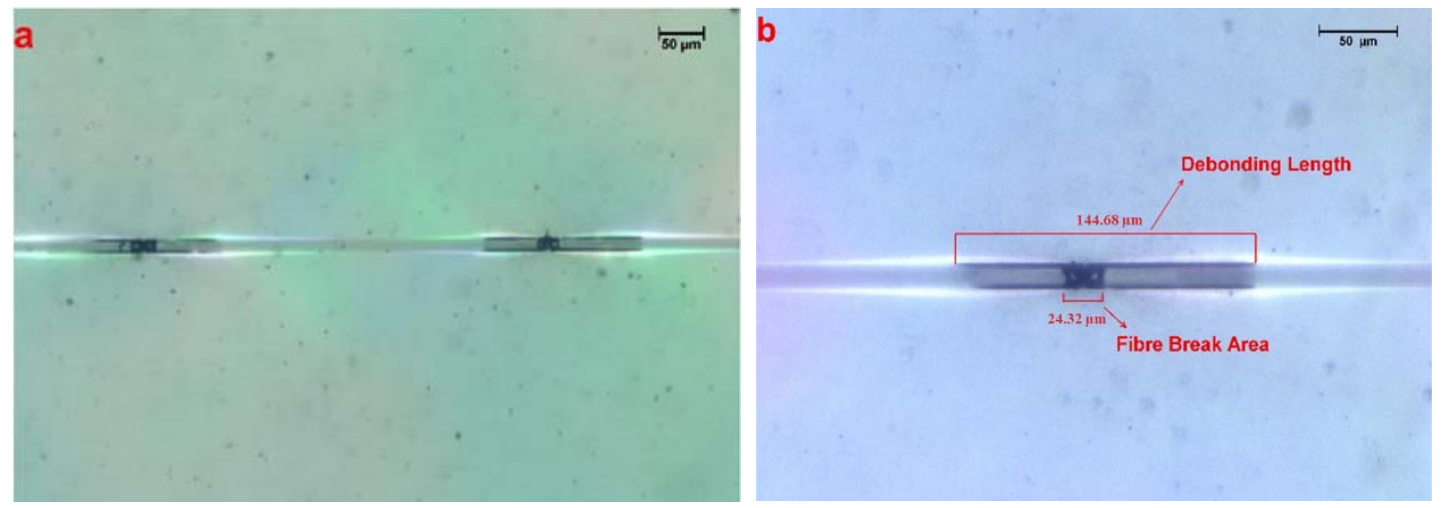

Figure 8 Optical micrograph showing the interface patterns (a) and the debonding length measurement (b) for the as-received basalt fibre/epoxy samples.

From Fig. 8-b it is possible to note that the maximum of the flat colour birefringence zone coincides with the black line present at the interface between the fibre and the epoxy matrix. The length of this zone has been considered for the debonding length measurement. The as-received basalt fibre/epoxy samples have shown the highest debonding length values. A symmetrical birefringence pattern has been found, Fig. 8-a, which confirms that the saturation level occurred at the end of fragmentation test. After the thermal treatment and the polymer plasma deposition process, a decrease and a lack in the flat colour zone were detected, respectively Fig. 9-a and Fig. 9-b. 


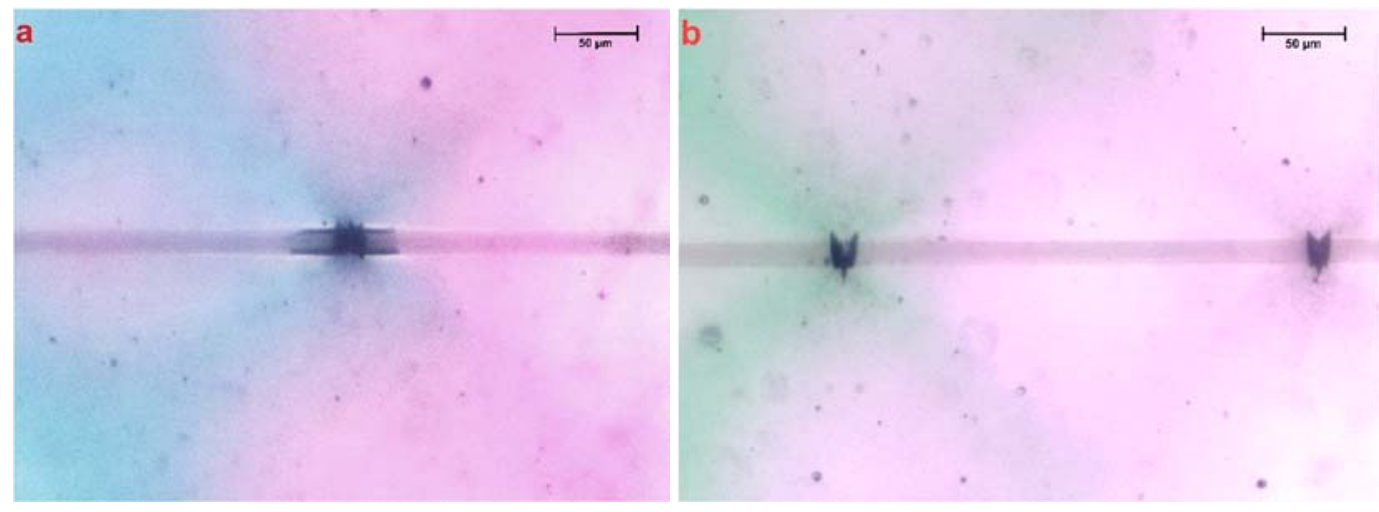

Figure 9 Optical micrograph showing the interface patterns for the thermally treated basalt fibre/epoxy (a) and the plasma treated basalt fibre/epoxy systems (b).

Table 4 reports all the debonding length values found for the different specimens, confirming the results highlighted by birefringence analysis.

Table 4 Debonding length, critical fragment length, and Interfacial Shear Strength of the untreated and treated basalt fibres.

\begin{tabular}{ccccc}
\hline \hline & $\mathbf{l}_{\text {debonding }}[\boldsymbol{\mu m}]$ & $\mathbf{l}_{\mathbf{c}}[\boldsymbol{\mu m}]$ & $\boldsymbol{\sigma}_{\mathbf{f}}\left(\mathbf{l}_{\mathbf{c}}\right)[\mathrm{MPa}]$ & IFSS [MPa] \\
As-received Basalt & $192.5 \pm 80$ & $675.2 \pm 109$ & $3591 \pm 55$ & $35.4 \pm 6$ \\
Basalt $\mathbf{4 0 0}{ }^{\circ} \mathbf{C}-\mathbf{~ 1 h}$ & $48 \pm 8$ & $353 \pm 13$ & $3282 \pm 27$ & $60.5 \pm 3$ \\
Basalt $\mathbf{4 0 0}{ }^{\circ} \mathbf{C}-\mathbf{~ 1 h}+\mathbf{~ P E C V D}$ & $23.5 \pm 14$ & $346 \pm 48$ & $3948 \pm 101$ & $75.4 \pm 10$ \\
\hline \hline
\end{tabular}

After the pp-TVS deposition, basalt fibres showed an increase in compatibility with the epoxy matrix evidenced by a significant reduction in the debonding phenomenon. The measurement of the critical fibre fragment length has been performed through optical microscopy. The value assumed by the critical fibre length reflects the stress transfer efficiency between the fibre and the matrix at the interface. For this reason, this estimation plays a crucial role in the assessment of the adhesion quality in a composite material. As reported by Ohsawa et al. [34], the critical fragment length has been evaluated using equation 3 :

$$
1_{c}=\frac{4}{3} \cdot \bar{l}
$$


where $\overline{1}$ is the average value of the fragment length, determined as the distance between the fibre ends. According to Kelly and Tyson, the interfacial shear strength value (IFSS) may be estimated using equation 4 :

$$
I F S S=\frac{\sigma_{f}\left(l_{c}\right) \cdot d}{2 \cdot l_{c}}
$$

where $\mathrm{d}$ is the fibre diameter, $1_{\mathrm{c}}$ is the critical fragment length and $\sigma_{\mathrm{f}}\left(l_{\mathrm{c}}\right)$ is the fibre strength at a length equal to the critical fibre length. Due to the impossibility to determine directly the tensile strength of a single basalt fibre at a length equal to the critical fragment length, an extrapolation of strength at critical length $1_{\mathrm{c}}$ has been implemented. In this study, an extrapolation method based on the Weibull cumulative distribution function has been used to evaluate the strength values at critical length [35][38]. Using the obtained two-parameter Weibull distribution, the strength values at critical length have been evaluated by equation 5 :

$$
\sigma_{f}\left(l_{c}\right)=\sigma_{f}\left(l_{0}\right)\left(\frac{l_{0}}{l_{c}}\right)^{-\frac{1}{m}}
$$

where $\mathrm{m}$ is the shape parameter of Weibull distribution for the tested gauge length $1_{0}$ of $40 \mathrm{~mm}, 1_{\mathrm{c}}$ is the critical fragment length and $\sigma_{f}\left(1_{0}\right)$ is the strength value at the gauge length. In Table 4 are reported all the critical fragment length values, the $\sigma_{\mathrm{f}}\left(\mathrm{l}_{\mathrm{c}}\right)$ values and the IFSS results obtained. The best results in terms of both critical fragment length and IFSS were found for the basalt fibres treated by the TVS plasma. From the results reported in table 4 it may be observed that a marked increase in the values of IFSS was produced after the deposition of the polymeric film. This reflects the results already discussed concerning break shape and debonding analysis. Comparing the critical fragment lengths and the IFSS values found for the thermally treated and the plasma treated basalt fibres, it is possible to note that the thermal treatment seems to have a positive effect on the interfacial adhesion of the basalt fibre with the epoxy matrix. Despite the sizing degradation carried out by the thermal exposure, a decrease in the critical length and an increase in the IFSS values has been produced compared to the values found for the as-received fibres. This is an interesting result because the sizing formulations are studied and optimized in order to promote the chemical bonding across the fibre/matrix interface. A possible explanation of this result may be ascribed to the topography modification produced after the fibre thermal exposure. As discussed above, an increase in the surface roughness of the thermally treated basalt fibres has been measured, Table 1. A mechanical interlocking action between the surface of the treated basalt fibre and the epoxy matrix may lead to the increase in the interface strength. In a recent study Thomason et al. [39] observed as compressive radial stress, generated during the cooling step of composites production, may create static frictional stresses able to affect 
the IFSS value. For this reason, it may be assumed that the increase in the fibres surface roughness leads to a growing importance of the friction stresses in the fibre/matrix adhesion measurement. A morphological investigation of the fracture surface has been performed using the FE-SEM. From an in-depth analysis of the different fracture surfaces, Figure 10 and Figure 11, once again it can be possible to confirm the higher adhesion of the plasma treated basalt fibre with the epoxy resin. Unlike the untreated and heat treated fibres, which showed partial pull-out and debonding phenomena (Fig. 10), the specimens characterized by the presence of the plasma treated fibres have been characterized by a total fibre/matrix adhesion (Fig. 11), ascribed also to an increased surface wettability of single fibres by epoxy resin due to formation of polar (hydroxyl and carbonyl) groups, after plasma coating. Potentially, there could be a chemical bonding at the fibre/epoxy interface due to -COOH species on the coated fibre.
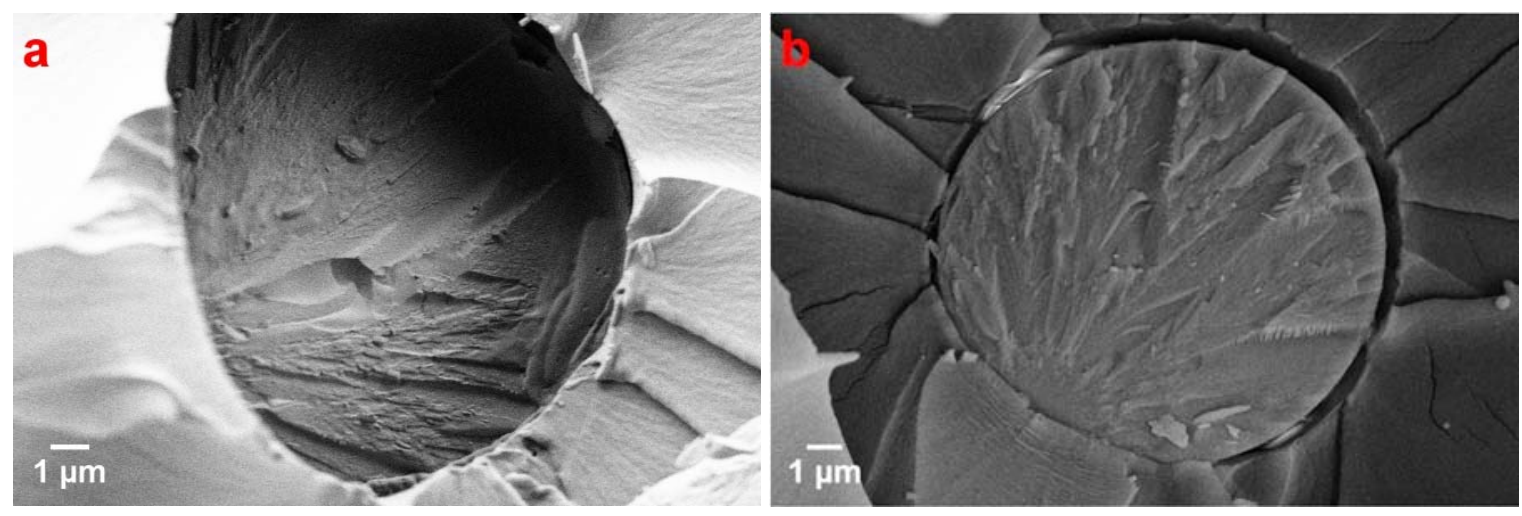

Figure 10 SEM micrographs detailing the fracture surface for the untreated (a) and thermally treated (b) single basalt fibre/epoxy systems.
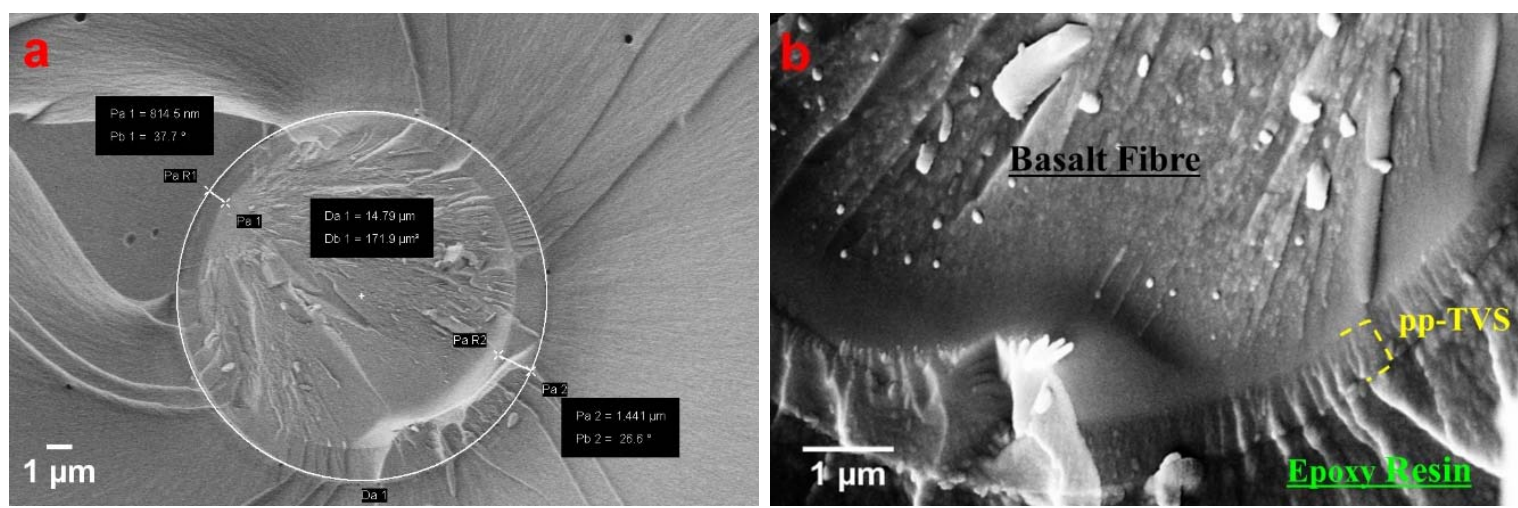

Figure 11 SEM micrographs detailing the fracture surface for the plasma treated single basalt fibre/epoxy systems: micrograph showing the thickness measurement of the pp-TVS deposited coating (a), a detailed view of the deposited pp-TVS coating at the fibre/matrix interface. 
Figure 11 shows as the plasma polymerization process is able to coat homogeneously the fibre surface. A measurement of the thickness of the polymer plasma TVS coating has been carried out through FE-SEM. A maximum and a minimum thickness value of $1.4 \mu \mathrm{m}$ and $0.8 \mu \mathrm{m}$, respectively, have been measured. This difference in thickness values is caused by the shadowing effect of the other fibres present in the bundle during the plasma deposition process.

\section{Conclusions}

The present experimental work provides a comparison between the interfacial adhesion properties of three different types of basalt fibers with epoxy matrix: (i) commercial fibres characterized by the presence of a sizing optimized for epoxy matrices; (ii) thermally treated fibres, in order to remove the commercial coupling agent; (iii) basalt fibres characterized by a polymer tetravinylsilane coating deposited through plasma polymerization process. The determination of the interfacial shear strength at fibre/matrix interface has been realized performing single fibre fragmentation tests. The study showed that the plasma deposition process is able to realize a polymeric coating able to promote the interfacial bond between the basalt fibers and the epoxy matrix. The adhesion qualities of the plasmatreated basalt fibres were found to be superior to those of commercial fibres. A reduction of the debonding and the critical fragment length as well as an increase in the value of IFSS have been obtained as a result of the pp-TVS. The study demonstrates how surface topography can play a significant role in the domain of fiber/matrix interfacial adhesion. An increase in the fibre surface roughness, in fact, is able to promote the formation of mechanical interactions between the fibre and the polymer matrix.

\section{References}

[1] "Global Basalt Fiber Market Analysis \& Trends - Industry Forecast to 2025." Research and Markets, 2017.

[2] A. Asadi, F. Baaij, H. Mainka, M. Rademacher, J. Thompson, and K. Kalaitzidou, "Basalt fibers as a sustainable and cost-effective alternative to glass fibers in sheet molding compound (SMC)," Compos. Part B Eng., vol. 123, pp. 210-218, 2017.

[3] V. Fiore, T. Scalici, G. Di Bella, and A. Valenza, "A review on basalt fibre and its 
composites," Compos. Part B Eng., vol. 74, pp. 74-94, 2015.

[4] J. Karger-Kocsis, H. Mahmood, and A. Pegoretti, "Recent advances in fiber/matrix interphase engineering for polymer composites," Prog. Mater. Sci., vol. 73, pp. 1-43, 2015.

[5] Q. Wu, R. Zhao, Q. Liu, T. Jiao, J. Zhu, and F. Wang, "Simultaneous improvement of interfacial strength and toughness between carbon fiber and epoxy by introducing amino functionalized ZrO2 on fiber surface," Mater. Des., vol. 149, pp. 15-24, 2018.

[6] R. L. Zhang, B. Gao, Q. H. Ma, J. Zhang, H. Z. Cui, and L. Liu, "Directly grafting graphene oxide onto carbon fiber and the effect on the mechanical properties of carbon fiber composites," Mater. Des., vol. 93, pp. 364-369, 2016.

[7] C. Wang, X. Ji, A. Roy, V. V. Silberschmidt, and Z. Chen, "Shear strength and fracture toughness of carbon fibre/epoxy interface: Effect of surface treatment,” Mater. Des., vol. 85, pp. 800-807, 2015.

[8] P. G. Jenkins, L. Yang, and Thomason, "Investigation of the effect of sizing on the tensile and interface properties of continuous basalt fibre and polypropylene," 18th Eur. Conf. Compos. Mater., no. June, pp. 24-28, 2018.

[9] D. W. Dwight, "Glass Fiber Reinforcements," in Comprehensive composite materials, Amsterdam: Elsevier Science Ltd, 2000, pp. 231-261.

[10] G. M. Nishioka, "Interaction of organosilanes with glass fibers," J. Non. Cryst. Solids, vol. 120, no. 1-3, pp. 102-107, 1990.

[11] J. L. Thomason, "The interface region in glass fibre-reinforced epoxy resin composites: 3. Characterization of fibre surface coatings and the interphase," Composites, vol. 26, no. 7, pp. 487-498, 1995.

[12] B. Wei, S. Song, and H. Cao, "Strengthening of basalt fibers with nano-SiO2-epoxy composite coating," Mater. Des., vol. 32, no. 8-9, pp. 4180-4186, 2011.

[13] B. Wei, H. Cao, and S. Song, "Surface modification and characterization of basalt fibers with hybrid sizings," Compos. Part A Appl. Sci. Manuf., vol. 42, no. 1, pp. 22-29, 2011.

[14] A. Greco, A. Maffezzoli, G. Casciaro, and F. Caretto, "Mechanical properties of basalt fibers and their adhesion to polypropylene matrices," Compos. Part B Eng., vol. 67, pp. 233-238, 2014. 
[15] F. Sarasini, J. Tirillò, C. Sergi, M. C. Seghini, L. Cozzarini, and N. Graupner, "Effect of basalt fibre hybridisation and sizing removal on mechanical and thermal properties of hemp fibre reinforced HDPE composites," Compos. Struct., vol. 188, no. September 2017, pp. 394-406, 2018.

[16] S. O. Lee, S. H. Choi, S. H. Kwon, K. Y. Rhee, and S. J. Park, "Modification of surface functionality of multi-walled carbon nanotubes on fracture toughness of basalt fiberreinforced composites," Compos. Part B Eng., vol. 79, pp. 47-52, 2015.

[17] Z. Liu, F. Zhao, and F. R. Jones, “Optimising the interfacial response of glass fibre composites with a functional nanoscale plasma polymer coating," Compos. Sci. Technol., vol. 68 , no. 15-16, pp. 3161-3170, 2008.

[18] J.-K. Kim and Y.-W. Mai, "High strength, high fracture toughness fibre composites with interface control - a review," Compos. Sci. Technol., vol. 41, pp. 333-378, 1991.

[19] M. T. Kim, M. H. Kim, K. Y. Rhee, and S. J. Park, "Study on an oxygen plasma treatment of a basalt fiber and its effect on the interlaminar fracture property of basalt/epoxy woven composites," Compos. Part B Eng., vol. 42, no. 3, pp. 499-504, 2011.

[20] V. Cech, A. Knob, T. Lasota, J. Lukes, and L. T. Drzal, "Surface modification of glass fibers by oxidized plasma coatings to improve interfacial shear strength in GF/polyester composites," Polym. Compos., pp. 1-8, 2017.

[21] V. Cech et al., "Enhanced interfacial adhesion of glass fibers by tetravinylsilane plasma modification," Compos. Part A Appl. Sci. Manuf., vol. 58, pp. 84-89, 2014.

[22] V. Cech, "Plasma-polymerized organosilicones as engineered interlayers in glass fiber/polyester composites," Compos. Interfaces, vol. 14, no. 4, pp. 321-334, 2007.

[23] V. Cech, R. Prikryl, R. Balkova, J. Vanek, and A. Grycova, "The influence of surface modifications of glass on glass fiber/polyester interphase properties," J. Adhes. Sci. Technol., vol. 17, no. 10, pp. 1299-1320, 2003.

[24] M. C. Seghini, F. Touchard, F. Sarasini, L. Chocinski-Arnault, D. Mellier, and J. Tirillò, "Interfacial adhesion assessment in flax/epoxy and in flax/vinylester composites by single yarn fragmentation test: Correlation with micro-CT analysis," Compos. Part A Appl. Sci. Manuf., vol. 113, no. April, pp. 66-75, 2018. 
[25] V. Cech, P. Horvath, J. Jancar, F. Schauer, and S. Nespurek, "Characterization of poly(methylphenylsilane) prepared by plasma polymerization," Macromol. Symp., vol. 148, pp. 321-332, 1999.

[26] L. J. Preston, M. R. M. Izawa, and N. R. Banerjee, "Infrared Spectroscopic Characterization of Organic Matter Associated with Microbial Bioalteration Textures in Basaltic Glass,” Astrobiology, vol. 11, no. 7, pp. 585-599, 2011.

[27] J. Kim, P. Seidler, L. S. Wan, and C. Fill, "Formation, structure, and reactivity of aminoterminated organic films on silicon substrates," J. Colloid Interface Sci., vol. 329, no. 1, pp. 114-119, 2009.

[28] V. Cech, J. Studynka, F. Janos, and V. Perina, "Influence of oxygen on the chemical structure of plasma polymer films deposited from a mixture of tetravinylsilane and oxygen gas,” Plasma Process. Polym., vol. 4, no. SUPPL.1, pp. S776-S780, 2007.

[29] G. Davidson, "The vibrational spectrum of tetravinylsilane," Spectrochim. Acta Part A Mol. Spectrosc., vol. 27, no. 7, pp. 1161-1169, 1971.

[30] F. Sarasini, J. Tirillò, and M. C. Seghini, "Influence of thermal conditioning on tensile behaviour of single basalt fibres," Compos. Part B Eng., vol. 132, pp. 77-86, 2018.

[31] B. W. Kim and J. a Nairn, "Observations of Fiber Fracture and Interfacial Debonding Phenomena Using the Fragmentation Test in Single Fiber Composites," J. Compos. Mater., vol. 36, no. 15, pp. 1825-1858, 2002.

[32] C. L. Schutte, W. Mcdonough, M. Shioya, M. Mcauliffe, and M. Greenwood, "The use of a single-fibre fragmentation test to study environmental durability of interfaces / interphases between DGEBA / mPDA epoxy and glass fibre : the effect of moisture," Composites, vol. 25, no. 7, pp. 617-624, 1994.

[33] S. Feih, K. Wonsyld, D. Minzari, P. Westermann, and H. Lilholt, "Testing procedure for the single fiber fragmentation test," Forskningscenter Risø. (Denmark. Forskningscenter Risoe. Risoe-R; No. 1483(EN)). Roskilde, pp. 1-30, 2004.

[34] T. Ohsawa, A. Nakayama, M. Miwa, and A. Hasegawa, "Temperature dependence of critical fiber length for glass fiber-reinforced thermosetting resins," J. Appl. Polym. Sci., vol. 22, no. 11, pp. 3203-3212, 1978. 
[35] R. Joffe, J. A. Andersons, and L. Wallström, "Strength and adhesion characteristics of elementary flax fibres with different surface treatments," Compos. Part A Appl. Sci. Manuf., vol. 34, no. 7, pp. 603-612, 2003.

[36] F. A. Ramirez, L. A. Carlsson, and B. A. Acha, "Evaluation of water degradation of vinylester and epoxy matrix composites by single fiber and composite tests," J. Mater. Sci., vol. 43, no. 15, pp. 5230-5242, 2008.

[37] N. E. Zafeiropoulos, "On the use of single fibre composites testing to characterise the interface in natural fibre composites," Compos. Interfaces, vol. 14, pp. 807-820, 2007.

[38] C. Guillebaud-Bonnafous, D. Vasconcellos, F. Touchard, and L. Chocinski-Arnault, "Experimental and numerical investigation of the interface between epoxy matrix and hemp yarn,” Compos. Part A Appl. Sci. Manuf., vol. 43, no. 11, pp. 2046-2058, 2012.

[39] J. L. Thomason, L. Yang, and R. F. Minty, "Are silanes the primary driver of interface strength in glass fibre composites? (exploring the relationship of the chemical and physical parameters which control composite interfacial strength)," Proc. 18th Eur. Conf. Compos. Mater., no. June, pp. 24-28, 2018. 